\title{
Phase equilibrium in shale including porous media effects
}

\section{Sandoval Lemus, Diego Rolando; Yan, Wei; Stenby, Erling Halfdan}

\section{Published in:}

Proceedings from the Abu Dhabi International Petroleum Exhibition \& Conference 2019

Link to article, DOI:

10.2118/197278-MS

Publication date:

2019

Document Version

Publisher's PDF, also known as Version of record

Link back to DTU Orbit

Citation (APA):

Sandoval Lemus, D. R., Yan, W., \& Stenby, E. H. (2019). Phase equilibrium in shale including porous media effects. In Proceedings from the Abu Dhabi International Petroleum Exhibition \& Conference 2019 [SPE-197278MS] Society of Petroleum Engineers. https://doi.org/10.2118/197278-MS

\section{General rights}

Copyright and moral rights for the publications made accessible in the public portal are retained by the authors and/or other copyright owners and it is a condition of accessing publications that users recognise and abide by the legal requirements associated with these rights.

- Users may download and print one copy of any publication from the public portal for the purpose of private study or research.

- You may not further distribute the material or use it for any profit-making activity or commercial gain

- You may freely distribute the URL identifying the publication in the public portal 


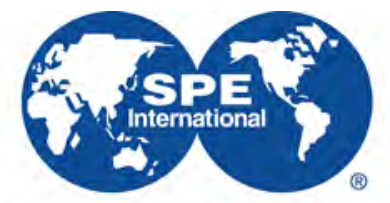

Society of Petroleum Engineers

\title{
SPE-197278-MS
}

\section{Phase Equilibrium in Shale Including Porous Media Effects}

\author{
Diego Rolando Sandoval Lemus, Wei Yan, and Erling Halfdan Stenby, Technical University of Denmark \\ Copyright 2019, Society of Petroleum Engineers \\ This paper was prepared for presentation at the Abu Dhabi International Petroleum Exhibition \& Conference held in Abu Dhabi, UAE, 11-14 November 2019. \\ This paper was selected for presentation by an SPE program committee following review of information contained in an abstract submitted by the author(s). Contents \\ of the paper have not been reviewed by the Society of Petroleum Engineers and are subject to correction by the author(s). The material does not necessarily reflect \\ any position of the Society of Petroleum Engineers, its officers, or members. Electronic reproduction, distribution, or storage of any part of this paper without the written \\ consent of the Society of Petroleum Engineers is prohibited. Permission to reproduce in print is restricted to an abstract of not more than 300 words; illustrations may
} not be copied. The abstract must contain conspicuous acknowledgment of SPE copyright.

\section{Abstract}

Fluid PVT is crucial to production of a petroleum reservoir. A complete PVT study requires high quality experimental measurement combined with subsequent efforts in PVT modelling. In contrast with the relatively matured PVT study for conventional reservoirs, PVT study for shale has a number of challenges. It is difficult to get representative fluid samples; and there are various speculations on how porous media can influence fluid PVT. For modeling shale PVT, it is necessary to consider the wall effects of the rock, mainly in terms of capillary pressure and adsorption. This requires robust algorithms as well as adequate procedures to integrate available experimental information into PVT modeling. Previously, we developed equilibrium calculation algorithms with capillary pressure and adsorption and modelled adsorption equilibrium in shale. Here we further integrate them into a PVT tool for PVT simulation, analysis of shale production, and gas injection in shale. The core module in the PVT calculation is flash with capillary pressure and adsorption. A robust flash module forms the basis of PVT simulation. The capillary pressure is described through the Young-Laplace equation. For adsorption, it requires a proper workflow to bridge the limited experimental measurement and the final modeling covering a wider range of hydrocarbons. It is recommended to model the available adsorption data for light gases using a theoretical adsorption model, and then extrapolate the model parameters to heavier hydrocarbons. The generated data from the theoretical model is then fitted to the simplified and more computationally convenient Langmuir model. The flash module can also be integrated into a slimtube simulator to study the porous media effects on gas injection applications. Capillary pressure alone lowers the bubble point pressure and the extent is system dependent. Nevertheless, even for systems with a moderate decrease, the change in the PVT properties in the two-phase region cannot be overlooked. Selective adsorption alters the bulk fluid composition and lowers the heavy components concentration in general. Adsorption is generally more pronounced in the gas region whereas capillary pressure is usually more obvious in the liquid region. Regarding the influence of capillary pressure on gas injection, it can be shown that the recoveries at pressures below the minimum miscibility pressure (MMP) are changed; however, the MMP does not seem to be affected due to the vanishing of capillarity effects. For the gas injection including adsorption, the results show that the recovery decreases if adsorption is considered. This is mainly due to adsorption of heavy components, and desorption of lighter components during the process. The heavy components stay in the adsorbed phase, and will not likely be recovered even at high injection pressures. The present study integrates our previous results on algorithms and modeling into a 
PVT tool for analyzing shale production. It can be used to infer what the initial fluid composition is in the shale reservoir, and to analyze how capillary pressure and adsorption influence shale production during a depletion procedure. Furthermore, the tool also allows a more advanced analysis for gas injection in shale.

\section{Introduction}

Importance of shale and tight reservoirs has dramatically increased since the beginning of the century due to shale boom in the United States. Technologies such as horizontal drilling and multistage hydraulic fracturing have allowed producing oil and gas commercially from these reservoirs. According to 2018 statistics from the U.S. Energy Information Administration (IEA), production from shale is around $70 \%$ of all the natural gas and $60 \%$ of all the crude oil produced in the United States. The increasing production trend is expected to be followed by other countries with large shale reserves as China and Argentina. Even though, production from shale reservoirs have been going on for more than a decade, the technology and knowledge is not nearly as mature as for the conventional oil reservoirs. The recoveries from shale reservoirs are roughly five times lower than the recoveries for conventional reservoirs. There still exist numerous challenges across all the disciplines of interest for shale production in order to increase its recovery. Kumar et al. (2013) simulated several production scenarios for liquid-rich shale reservoirs and show that the fracture length and fluid PVT are the most sensitive and crucial factors that control the production.

PVT modeling for shale has additional challenges due to strong solid-fluid interactions with the porous media. The pore sizes of shale and ultra-tight reservoirs range on the nanometer scale. At such conditions, the fluids inside the rock will experience high capillary forces resulting in big pressure differences. Confinement effects due to restriction of geometry will modify the phase behavior and density of the fluids. In addition, the heterogeneity and high organic content in shale introduces adsorption effects that will alter the composition of the fluid over the time as this is produced. All the effects mentioned above will have an impact on the PVT properties of the fluid, and the extent will vary depending on the fluid, rock and reservoir conditions. Fischer and Israelachvili (1980) demonstrated experimentally the applicability of the Kelvin equation for pure components for radii as low as $4 \mathrm{~nm}$. Recent efforts have measured successfully the saturation point of hydrocarbons inside nano-porous materials using differential scanning calorimetry (DSC) techniques (Luo et al. 2016a-b, Regueira et al. 2019). The binary multicomponent case is more challenging due to mixing limitations inside the porous material. Nevertheless, measurements at low pressure using DSC have also been performed showing deviations with respect the bulk case (Luo et al. 2018). From the modeling point of view, Shapiro and Stenby (1998) extended the Kelvin equation to multicomponent mixtures; Nojabaei et al. (2014) presented a reservoir simulation showing the impact of the capillary pressure on the oil production and Sandoval et al. (2016) showed changes on the phase envelope except on the critical point,

Influence of adsorption on phase behavior has also been studied using DSC showing dramatic changes on the bubble point temperature of pure components and mixtures (Pathak et al. 2017a-c). Inclusion of adsorption into phase equilibrium calculations is not an easy task since one more phase is considered in the system. Cabral et al. (2004) presented an algorithm to calculate phase equilibrium in systems with multiple adsorbed and bulk phases at fixed volume and temperature. Dong et al. (2016) presented the impact of the adsorption film on the capillary radii showing that the capillary pressure effect is enhanced. Sandoval et al. (2018) presented an algorithm including two bulk phases with a capillary pressure difference and additional adsorbed phase at a constant pressure and temperature. The results show large differences with respect the bulk case especially when a gas phase is present in the system.

Interest of gas injection on shale reservoirs has increased in the past years since Huff-N-Puff studies have shown that there is a high potential to improve oil recovery on the current wells (Meng et al. 2015, Li et al. 2016, Hamdi et al 2018, Wang and Yu 2019, Ganjdanesh et al. 2019). Here, we have used the tool developed by Sandoval et al (2018) to further investigate depletion scenarios through Differential Liberation (DL) and constant volume depletion (CVD) tests; and gas injection of methane using 1D-slimtube 
simulations. The results shed light into the main effects of the capillary pressure and adsorption on PVT modeling for different reservoir fluids at different applications. The paper is divided into three main sections. The Methods section presents an overview of the phase equilibrium calculations, parametrization of the adsorption models and general equations for 1D-gas injection simulation. The Results section discusses the findings for the depletion case of two black oils and one gas condensate using DL and CVD tests simulation. Furthermore, slimtube simulations considering capillary pressure and adsorption are also presented. Lastly, the Conclusions section summarizes the main findings and give recommendations on which porous media effects on phase behavior should be taken into account depending on the system, fluid, and type of application.

\section{Methods}

\section{Flash Including Capillary Pressure and Adsorption}

Phase split calculations are generally the innermost calculation of simulation processes including multiple phases. The solution to the flash problem provides us with physical properties such as density, composition, volume saturations, etc, required to solve the governing equations of the simulated process. For standard PVT and slimtube simulations, a conventional two-phase flash at a specified $T$ and $P$ is normally used since cases with more than two phases are rare. When more phases are present in the system modifications to the flash procedure are required. For multiple bulk phases, the multiphase flash can be employed. In the case of PVT and 1D-slimtube simulations including porous media effects, the flash is modified to include capillary pressure effects and to acknowledge the existence of an additional adsorbed phase. In this work, we have used a slight modification to the work proposed by Sandoval et. al (2018). Instead of the excess adsorbed phase, we use the total adsorbed phase, which is more useful for the PVT and slimtube simulations where the 'non-mobile' phase corresponds to the absolute adsorbed phase. At equilibrium, a system with two bulk phases and an adsorbed phase should should satisfy the following conditions:

$$
\begin{array}{cc}
\text { mass balance } & \beta^{g} y_{i}+\beta^{l} x_{i}+\beta^{a} w_{i} \\
\text { phase equilibrium } & f_{i}^{g}=f_{i}^{l}=f_{i}^{a} \\
\text { capillary pressure } & P_{g}-P_{g}=\frac{2 \sigma}{r_{c}} \\
\text { summation of mole fractions } & \sum_{i}^{N_{C}} y_{i}=\sum_{i}^{N_{c}} x_{i}=\sum_{i}^{N_{c}} w_{i}=1
\end{array}
$$

where $\beta$ is the phase mole fraction, $f$ the fugacity, $P^{g}$ the gas pressure, $P^{l}$ the liquid pressure, $\sigma$ the interfacial tension, $r^{c}$ the capillary radius, and $y, x$ and $w$ the vapor, liquid and adsorbed phase mole fraction respectively. Note that the Young-Laplace equation inside a capillary tube has been used in equation (3). Full wetting of the liquid phase have been assumed, and the interfacial tension was calculated using the parachor model developed by McLeod and Sudgen (1924).

We denote the surface area of the absorbent by $A$, the volume of the bulk mixture by $V$, and the geometric factor of the porous media by $G_{f}$. The geometric factor is a property of the porous media and it is equal to its surface area-volume ratio $\left(G_{f}=A / V\right)$. For a capillary tube, it is equal to $2 / r_{\mathrm{c}}$. In the procedure presented in Sandoval et al. (2018), the geometric factor of the system is specified and the calculations are performed at a constant pressure and temperature. In this problem formulation, the feed is in a porous media, e.g., a capillary tube. We can imagine that there is a piston (or mercury) varying the total volume of the substance to reach a final pressure equal to the specified one. This means that the area in contact with the bulk phase is not fixed, but the overall $G_{\mathrm{f}}$ is the same (or $V^{\text {solution }}=V_{\text {pore }}$ ). The central idea of the algorithm is to couple twophase flash calculations, adjusting the bulk composition in an outer loop with the adsorbed phase as follows: 


$$
z_{i}^{b}=\frac{z_{i}^{f}-\beta^{a} w_{i}}{1-\beta^{a}}
$$

where the compositions of the adsorbed phase are calculated using an adsorption model, here the Multicomponent Langmuir (ML) is employed. The new bulk composition is used to calculate the new properties using a partial update of the two-phase flash (i.e. one-step local Gibbs reduction). An updated adsorbed phase fraction is obtained from the molar volumes $V_{m}$, surface excess $\Gamma_{e x c}$ and the specified geometric factor

$$
\beta^{a}=\frac{G_{f} V_{m} \Gamma_{e x}}{1+G_{f} V_{m} \Gamma_{e x}}
$$

The new adsorbed phase mole fraction is substituted back to equation (5) for the next iteration. The successive substitution continues until convergence. Sandoval et al. (2018) also suggested using quadratic update in the inner loop for faster convergence although the whole algorithm is still successive substitution.

\section{Parameter Estimation for Adsorption Modeling in Shale}

Adsorption data for shale and for tight reservoirs in general is scarce in the open literature. The experimental measurements are extremely difficult due to low adsorption capacities compared to industrial adsorbents such as activated carbon and silica gel. In addition, high pressure and high temperature conditions make the task even more challenging. Gasparik et al. (2014) presents an excellent overview of current challenges in an inter-laboratory study. Large differences were found in the reported adsorption measurements for methane, ethane and carbon dioxide from different laboratories using the same rock sample as a starting point. For methane, the differences are as large as 50\%, whereas for ethane and carbon dioxide can be larger than $100 \%$.

Experimental gas adsorption measurements for hydrocarbons larger than propane in shale are virtually non-existing. Extremely high temperatures are needed to physically measure its adsorption at reservoir pressure conditions. In practice, this is an impossible task. Therefore, simulation and modeling tools are required to estimate its adsorption at reservoir conditions. Sandoval et al. (2018) proposed to fit the Langmuir parameters using pseudo-experimental data generated by the multicomponent potential theory of adsorption (MPTA) proposed by Shapiro and Stenby (1998). In principle MPTA model parameters are temperature independent, and more importantly they follow a linear correlation with respect the carbon number (or molecular weight) for hydrocarbons. In other words, parameters for larger hydrocarbons at different temperatures can be roughly estimated from smaller hydrocarbons experimental data. The adsorption data from Wang et al. (2015) served as a starting point to fit the MPTA energy parameters for methane and ethane, and later extrapolated to larger hydrocarbons. We are aware that this approach may introduce some errors on the results, but it should capture the general behavior of the competitive adsorption within hydrocarbons. In Sandoval et al. (2018) the extrapolation was made for hydrocarbons up to $\mathrm{C}_{16}$, here we have extend the approach for larger hydrocarbons using the molecular weight to extrapolate the Langmuir parameters. The Langmuir equation has the following form:

$$
n^{a d s}=n_{i}^{\max } \frac{k_{i} f_{i}}{1+\sum_{j} k_{j} f_{j}}
$$

where $n$ is the adsorbed amount per unit of adsorbent, $n_{i}{ }^{\max }$ the maximum adsorption capacity, and $k_{i}$ the energy parameter of adsorption. The $k$ parameter can be related to the enthalpy and entropy of adsorption (citation) using the following expression:

$$
\ln k_{i}(T)=\ln A_{i}-\frac{E_{i}^{a}}{R}\left(\frac{1}{T}\right)
$$


where $A$ is the entropy contribution parameter and $E^{a}$ is the differential enthalpy of adsorption. Parameters $A$ and $E$ were fitted to pseudo-experimental data generated by MPTA at different temperatures for several hydrocarbons. Similar to the energy parameter of the MPTA model, it was found that $A$ and $E$ in equation (8) are linearly correlated to the molecular weight for hydrocarbons allowing its extrapolation for reservoir fluids using its molecular weight. Furthermore, the parameter $n_{i}^{\max }$ can be obtained using the volume of adsorption $V^{a d s}$ and the maximum density of the adsorbed phase. The volume of adsorption can be measured experimentally or by fitting experimental adsorption data; the maximum density is approximated by the co-volume.

$$
n_{i}^{\max }=\frac{V^{a d s}}{b}
$$

In this study, the co-volume parameter of the Peng-Robinson EoS was used. Therefore, it was also employed to fit MPTA to experimental data, generate the pseudo-experimental data at different temperatures, and fit the Langmuir adsorption parameters on equation (8). The parameters for the reservoir fluids used here are summarized on Table A-1 to Table A-3 of Appendix A.

\section{D-Gas Injection through Slimtube Simulation}

The slimtube simulation follows the following mass conservation equation (8) with the assumption of nondeformable porous media, no capillary, and dispersion or diffusion effects

$$
\frac{\partial C_{i}}{\partial t}+\frac{\partial\left(v_{D} F_{i}\right)}{\partial x}=0
$$

In the above equation, $C_{i}$ and $F_{i}$ are overall molar density and molar flux respectively, and $v_{D}$ is the dimensionless velocity. The time and space coordinates have been modified in order to obtain a nondimensional problem.

$$
t=\frac{v_{\text {inj }} t^{\prime}}{\phi L}=P V I \text { and } \quad x=\frac{x^{\prime}}{L}
$$

An implicit single point upstream (SPU) or explicit SPU scheme can be employed to discretize equation (10) as follows:

$$
\begin{array}{ll}
\frac{C_{i, k}^{n+1}-C_{i, k}^{n}}{\Delta t}+\frac{v_{D, k} F_{i, k}^{n+1}-v_{D, k-1} F_{i, k-1}^{n+1}}{\Delta x}=0 & \text { (ISPU) } \\
\frac{C_{i, k}^{n+1}-C_{i, k}^{n}}{\Delta t}+\frac{v_{D, k} F_{i, k}^{n}-v_{D, k-1} F_{i, k-1}^{n}}{\Delta x}=0 & \text { (ESPU) }
\end{array}
$$

The implicit scheme form corresponds to the cell-to-cell simulation. Furthermore, it should be noted that the dimensionless velocities become one if we assume no volume change (NVC) on mixing. The above equations can be reformulated as

$$
\begin{aligned}
C_{i, k}^{n+1} & =C_{i, k}^{n}+\frac{\Delta t}{\Delta x}\left(v_{D, k}^{n+1} F_{i, k}^{n+1}-v_{D, k-1}^{n+1} F_{i, k-1}^{n+1}\right) \\
C_{i, k}^{n+1} & =C_{i, k}^{n}+\frac{\Delta t}{\Delta x}\left(v_{D, k}^{n+1} F_{i, k}^{n}-v_{D, k-1}^{n+1} F_{i, k-1}^{n}\right)
\end{aligned}
$$

During the cell-to-cell simulation, a certain amount of injection fluid is added to the first cell. Then the extra volume is moved to the downstream neighboring cell, and the procedure is repeated until the extra volume reaches the last cell, and then produced. If it is NVC, it can be shown that all the extra volumes will be the same as the injection volume. In other words, the mixing and phase partitioning in each cell does not cause extra volume change. This makes the computation much simpler.

For the ESPU scheme, the fluxes are calculated using those from the previous step. It means that for the first time step and in the first cell, the influx is from the boundary which is always the same, the 
outflux is zero as it is from the previous time-step. There is a lag in time for the flux calculation and the corresponding physical picture is not very clear. Higher order explicit methods using total variation diminish (TVD) schemes can improve the resolution of the simulation by increasing accuracy and stability while maintaining the same number of grid blocks. Here we used the same approached used by Yan et al. (2012) were a formulation similar Thiele et al. (1997) is employed using the Van Leer limiters.

No matter if, it is the implicit or the explicit scheme, the concentration $C$ at time level $n+1$ is always the input for flash calculation. When considering adsorption, some assumptions may introduce certain errors in the results. First, the flash procedure considered here assumes a constant geometric factor, which implies that the extra volume produced at each step increases the area proportionally and the resulting area at the solution is slightly larger than the real system area. Second, we assume no mobility of the adsorbed phase on the flux terms. The exchange of components from the adsorbed phase to the mobile bulk phases happens exclusively during the flash procedure. In principle, modified fractional flow functions can be introduced to account partial mobility of the adsorbed phase to the neighboring cells. On the other hand, our assumption simplifies the implementation of the simulation since only the flash routines have to be replaced.

\section{Results}

Definition and specification of the problem is crucial in order to have a comprehensive comparison of the PVT results and slimtube simulations. To compare the calculations with and without capillary pressure and adsorption will depend on what we consider as feed. Table 1 summarizes different feed and effects scenarios that are worthwhile studying by either PVT lab experiments or simulation studies.

Table 1-Description of cases including feed and considered effects.

\begin{tabular}{lllll}
\hline Case & Feed & $\boldsymbol{P}_{c}$ & Ads & Remark \\
\hline I & $z^{f}$ & $\mathrm{X}$ & $\mathrm{X}$ & Actual situation in field \\
II & $z^{b}$ & & $\begin{array}{l}\text { Common situation in PVT lab (bulk } \\
\text { sample) }\end{array}$ \\
& & & $\begin{array}{l}\text { PVT lab with adsorbed phase (core } \\
\text { sample) }\end{array}$ \\
III & $z^{f}$ & & PVT lab (case II) + simulated $P_{c}$ effect \\
IV & $z^{b}$ & $\mathrm{X}$ & & $\begin{array}{l}\text { PVT lab (case III) + simulated } \\
\text { adsorption effect }\end{array}$ \\
V & $z^{f}$ & & $\mathrm{X}$ &
\end{tabular}

The 'real' (or the closest approximation) case happening in the reservoir is case I. The overall feed composition is subject to capillary and adsorption effects, it is not possible to perform such experiment in the $\mathrm{lab}$ at the current stage and simulation is thus required. Case II shows the most common situation in the lab when the fluid sample corresponds to the mobile bulk fluid. The sample is generally obtained from one of the production wells and the PVT experiment is performed without further modification of the composition. Case III is also possible to perform experimental PVT tests, and the feed composition is obtained either by a core sample or by adjusting the bulk composition with an 'added' adsorbed phase. Case IV uses the bulk composition entirely neglecting the adsorbed phase and only considering capillary pressure effects through simulation. Case V is a hypothetical scenario that takes into account the overall composition (case III) but neglects the capillary pressure and only adsorption effects are considered.

Throughout the Results section, the five cases will be compared under different circumstances. The fluid compositions presented in this work refer to the overall feed $z^{f}$ and they are converted to $z^{b}$ when needed using the flash procedure including adsorption. The section has three subsections. The first discusses the results of standard PVT simulations to get an insight on the oil and gas production during natural depletion. Two black oil fluids with different gas oil ratio (GOR) from the Eagle Ford field are investigated 
using differential liberation (DL) tests, and one gas condensate from the Eagle Ford field, is investigated using constant volume depletion (CVD) tests. The second subsection present results for the 1D-slimtube simulations including the capillary pressure effect on the phase equilibrium, and the third subsection shows results for 1D-simulations including the effect of adsorption.

\section{PVT Modeling for depletion}

Two black oil reservoir fluids from the Eagle Ford field taken from Orangi et al. (2011) were tested using DL simulation experiments. The first correspond to a $1000 \mathrm{stb} / \mathrm{scf}$ GOR and the second to a $500 \mathrm{stb} / \mathrm{scf}$ GOR. Both are described in Table A-1 and Table A-2 in the Appendix, respectively. The composition of the fluid is taken as the overall composition $z^{f}$ as a starting point and $z^{b}$ is calculated at the reservoir temperature and initial pressure using the flash algorithm including adsorption presented in the Methods section. The results are presented in Fig. 1 and Fig. 2 for four different cases that correspond to cases I to IV in Table 1.
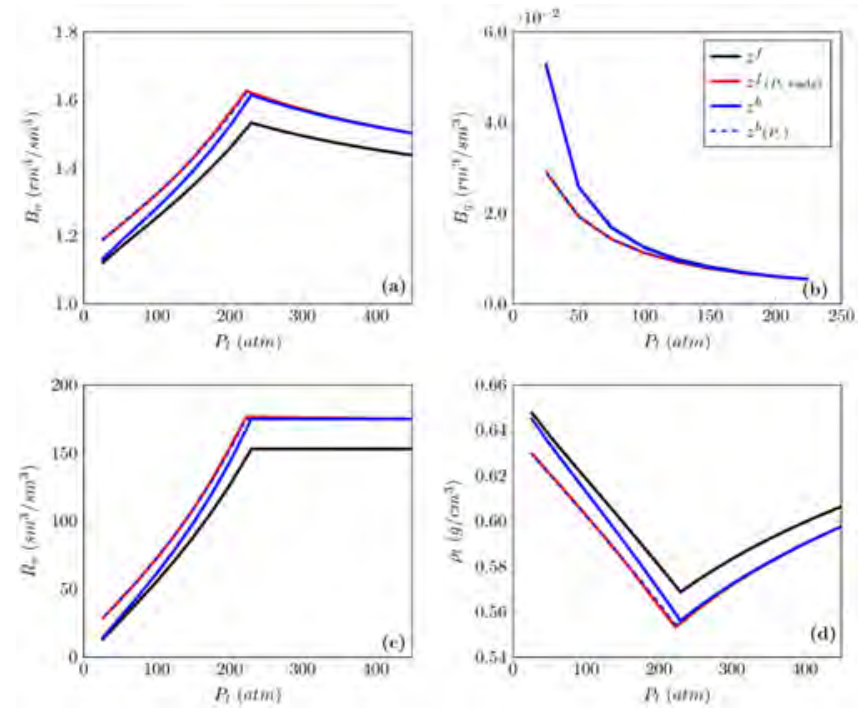

Figure 1-(a) Oil formation volume factor $\boldsymbol{B}_{o}$, (b) Gas formation volume factor $\boldsymbol{B}_{g}$, (c) Solution gas-oil ratio $\boldsymbol{R}_{s}$, and (d) liquid density $\rho_{l}$ for DL experiment simulation at $T=400 \mathrm{~K}$ using the $1000 \mathrm{stb} / \mathrm{scf}$ GOR Eagle Ford fluid. Capillary radius $r_{c}=10 \mathrm{~nm}$.
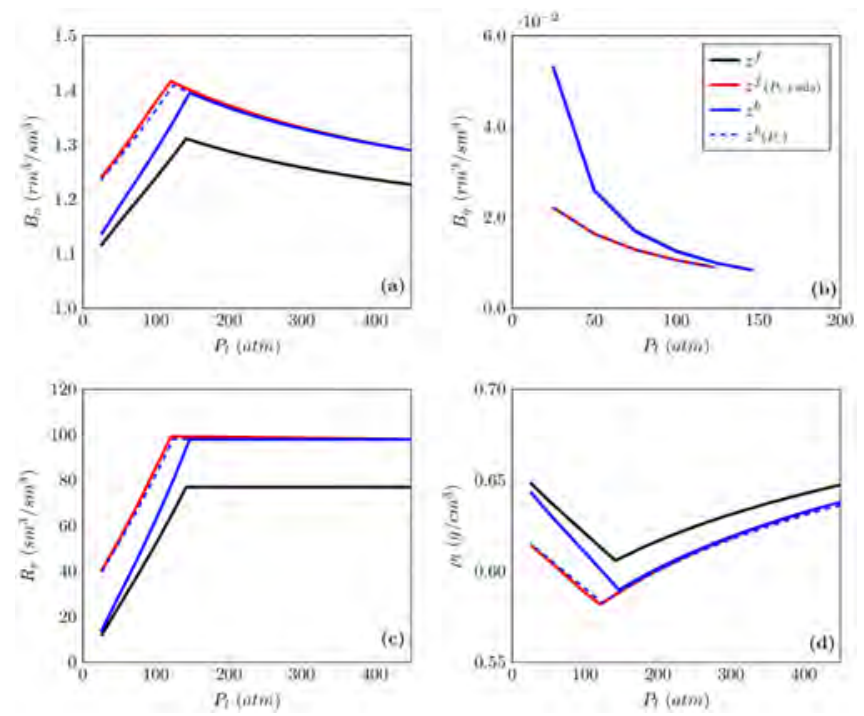

Figure 2-(a) Oil formation volume factor $\boldsymbol{B}_{o}$, (b) Gas formation volume factor $\boldsymbol{B}_{g}$, (c) Solution gas-oil ratio $\boldsymbol{R}_{s}$, and (d) liquid density $\rho_{l}$ for DL experiment simulation at $T=400 \mathrm{~K}$ using the $500 \mathrm{scf} / \mathrm{stb}$ GOR Eagle Ford fluid. Capillary radius $r_{c}=5 \mathrm{~nm}$. 
The case considering no effect and $z^{f}$ as the overall composition (case III) gives the most different results for all the properties among them. The other three cases are closer to each other. Case I and case IV are almost identical, and very few differences can be observed for both fluids, even for the $500 \mathrm{scf} / \mathrm{stb}$ fluid at a capillary radius of $5 \mathrm{~nm}$. This means that the effect of adsorption and desorption during depletion of black oil systems is small since case IV essentially ignores the adsorbed phase during the calculation. The most important consideration is the correct use of the initial composition. If one uses the bulk composition, adsorption effects can be neglected, but if one uses composition $z^{f}$ the adsorption phase should be carried through the calculation. Either use $z^{b}$ and ignore the adsorbed phase or considered the overall composition $z^{f}$ and carry on the calculations including the adsorbed phase. This suggests that the capillary pressure effect and adsorption effect may be decoupled for the description of this process. In other words, it might be possible to approximate the process by adding one effect on top of the other. One small difference observed for case I is the slight increase of the solution gas-oil ratio $R_{s}$ during the single-phase region due to desorption of lighter components.

Case II shows some deviation with respect case I and case IV, especially around the saturation point and the two-phase region. This difference is the result of the capillary pressure effects. The bubble point is suppressed and the single-phase region production is extended to lower pressures. The curves appear to be offset by a similar magnitude to the suppression of the bubble point. Furthermore, it can be observed that the difference on the formation volume factors $B_{o}$ and $B_{g}$, solution gas-oil ratio $R_{s}$, and liquid density is increased as the capillary radius decreases. Furthermore, the $B_{o}$ increases for the cases where capillary pressure is considered. This happens because the gas phase (non-wetting) has a higher pressure than the liquid phase (wetting) and there is a migration of lighter components from the gas phase to the liquid phase.

CVD simulations were also performed to a gas condensate fluid from the Bakken fluid taken from Orangi et al. (2011). The fluid has a condensate to gas ratio (CGR) of $150 \mathrm{MMscf} / \mathrm{stb}$. Fig. 3 show dramatic changes are observed in comparison to the DL simulation. For the gas condensate case, the adsorption effect is more pronounce than the capillary pressure effect. The differences between case I and case V are small, similar to the differences between case II and IV. Suggesting that the capillary pressure effect is not as strong as in the black oil cases. Furthermore, contrary to the black oil experiments, case I and case II are quite different which suggests that the adsorption/desorption effects during the process are crucial and should not be neglected. Differences on the solution oil to gas ratio $r_{s}$ and production of $y^{7+}$ fraction can also be noticed along the curves. Before the saturation point, the fluid suffers a leaning of components resulting in a lower rs and $y^{7+}$ production. After the saturation point, both properties are close to each other with minor differences. The most dramatic difference is observed in the liquid dropout $V_{r l}$ being three times higher for the case considering the overall feed $z^{f}$ without considering additional effects, and around 50\% higher for the case considering just the bulk phase $z^{b}$ with and without capillary pressure. The decrease of the liquid dropout shows that the adsorption has a negative impact on the production from gas condensates caused by the leaning of the gas, and the capillary pressure a positive effect due to capillary condensation. 

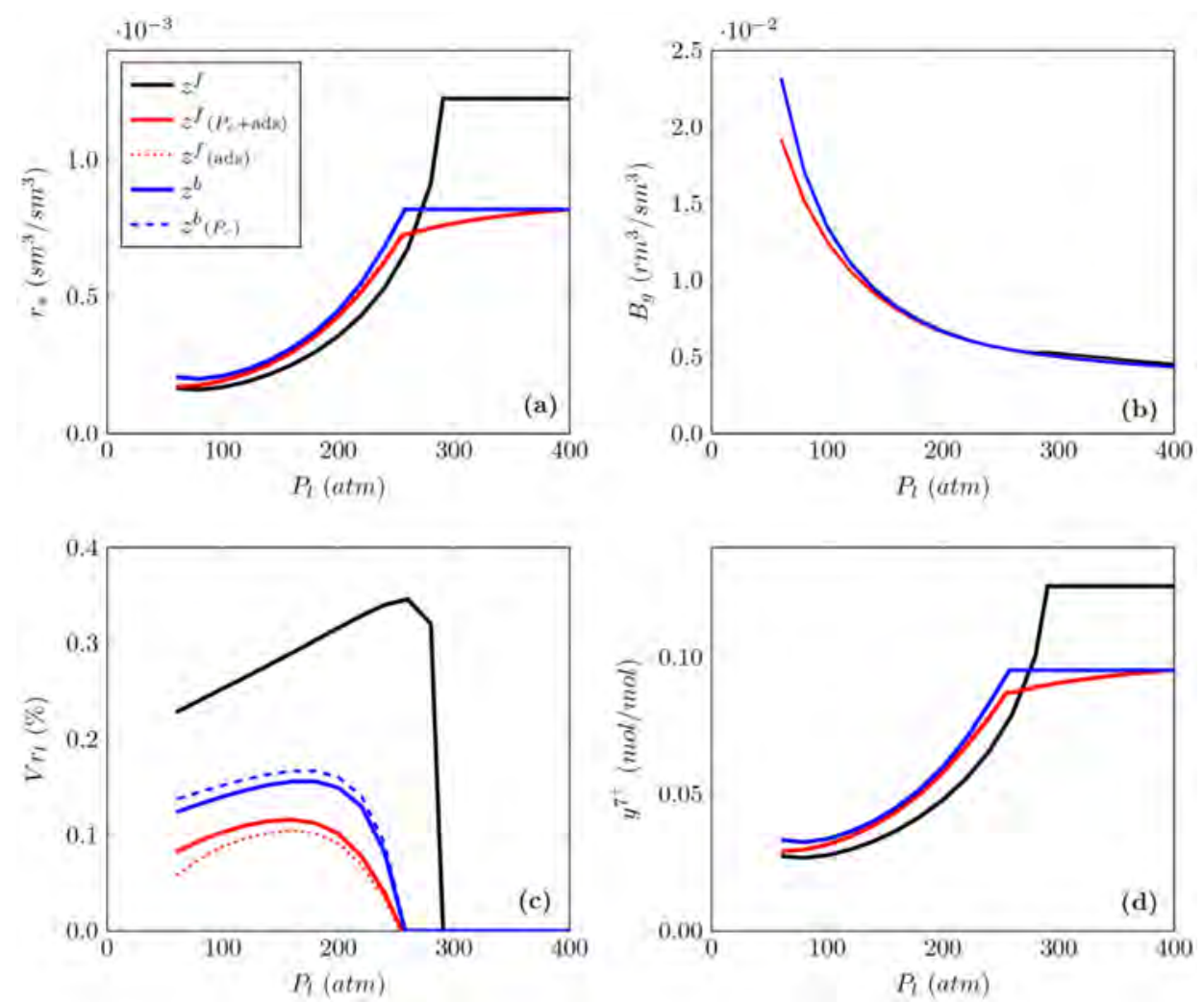

Figure 3-(a) oil-gas ratio rs, (b) Gas formation volume factor $\mathrm{Bg}$, (c) liquid drop out $\mathrm{Vrl}$, and (d) y7+ fraction in the producing stream for a CVD experiment simulation at T=420\#K using $150 \mathrm{MMscf} / \mathrm{stb}$ CGR Eagle Ford fluid. Capillary radius $r_{c}=10 \mathrm{~nm}$.

\section{Slimtube Simulation Including Capillary Pressure}

1D-slimtube simulations including the effect of capillary pressure on phase behavior are presented in order to study the MMP at different capillary radii and $T=400 \mathrm{~K}$. Two black oils were tested and their description are presented on Table A-1 and Table A-3. One corresponds to the $500 \mathrm{scf} / \mathrm{stb}$ GOR Eagle Ford fluid, and the other to a black oil fluid from the Bakken field taken from Nojabaei et al. (2013). The explicit scheme with TVD limitation described in the Method section was employed in all slimtube simulations including capillary pressure. It is important to mention that the capillary pressure difference was not considered in the flow equations but only on the phase equilibrium calculations. This is an approximation, but it is convenient to implement since only the flash part of the code needs to be modified, while the overall structure of the flow equations remains the same.

Fig. 4 and Fig. 5 show displacement plots for the Eagle Ford fluid at two different pressures using pure methane as the injection gas. Results show that solutions appear to be self-similar with an offset proportional to the magnitude of the capillary pressure. The capillary pressure differences on the injecting tie line are as high as 25/44/82 atm for the cases of 10/5/2 nm respectively, and around 13/22/41 atm for the initial tie line. When the injecting pressure is increased to $400 \mathrm{~atm}$ (Fig. 5) the capillary pressure between the liquid and the gas phase decreases. The injecting and initial tie line capillary pressure differences fall to 7/13/28 and $0.5 / 0.6 / 0.7 \mathrm{~atm}$ for $10 / 5 / 2 \mathrm{~nm}$ capillary radii respectively. As the pressure is further increased, the critical region is approached and the capillary pressure vanishes since the gas and liquid densities become almost identical, resulting in the disappearance of the gas-liquid interface. 

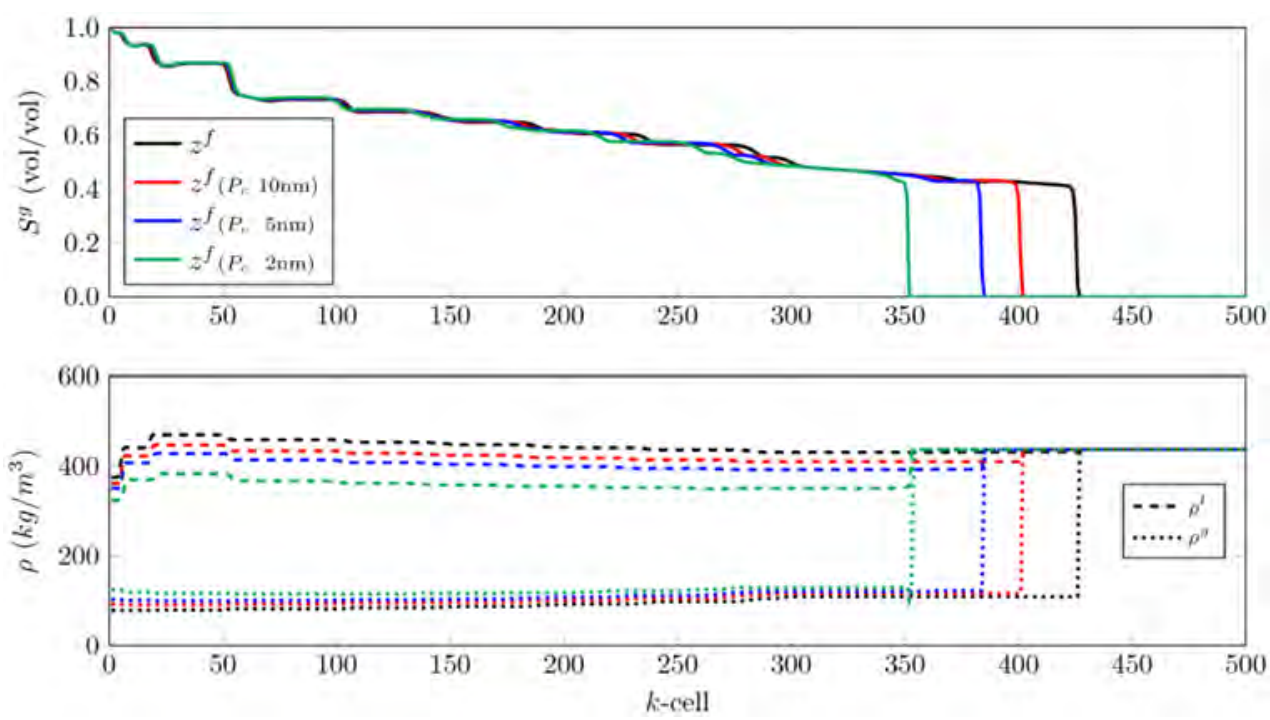

Figure 4-[Top] gas saturation and [Bottom] density displacement profiles after $0.5 \mathrm{PVI}$ at $140 \mathrm{~atm}$ using $500 \mathrm{GOR}$ Eagle Ford fluid at different capillary radii.
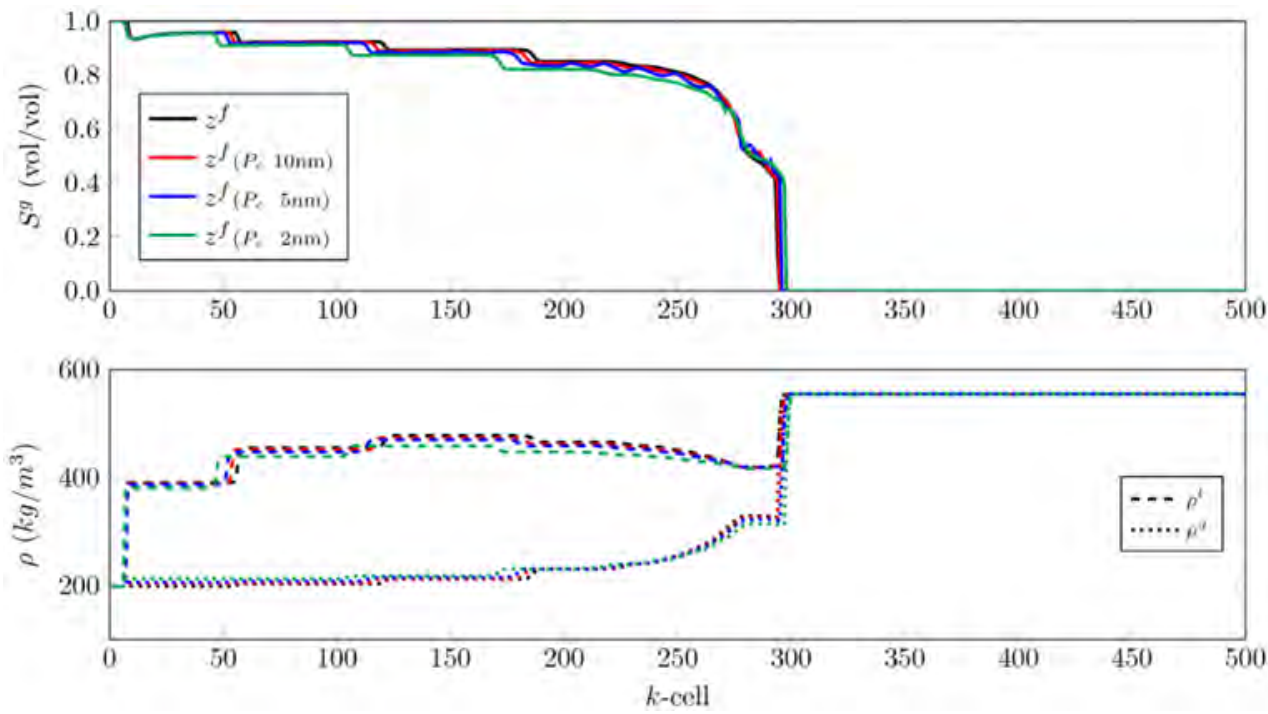

Figure 5-[Top] gas saturation and [Bottom] density displacement profiles after $0.5 \mathrm{PVI}$ at $400 \mathrm{~atm}$ using $500 \mathrm{GOR}$ Eagle Ford fluid at different capillary radii.

The MMP results are summarized in Fig. 6 and Fig. 7. They show the $C^{7+}$ recovery at different pressures and different pore volumes injected (PVI) for a fixed pressure respectively. The dimension of the system used is of 500 grid blocks and the results were extrapolated to an infinite number of grid blocks by plotting $1 /$ $N^{0.5}$ against the recovery (Stalkup 1990). Fig. 6 and Fig. 7 show that at low injection pressures, the recovery is higher for the cases including capillary pressure. After a determined pressure, an overlap on the curves considering capillary pressure occurs (around $350 \mathrm{~atm}$ for the Eagle Ford fluid and $225 \mathrm{~atm}$ for the Bakken fluid) and the recoveries decrease until a common MMP is reached where all the curves intersect again at $100 \%$ recovery. It is worthwhile noticing that the Eagle Ford fluid is an extreme case of a very heavy oil with high capillary pressures that may not reflect the general case for shale oils. The differences on the recovery curves for the Bakken fluid in Fig. 6 are more moderate in comparison to the Eagle Ford fluid. The only exception is the case with a capillary radius of $2 \mathrm{~nm}$, which is also an extreme case and additional confinement effects should be considered. 

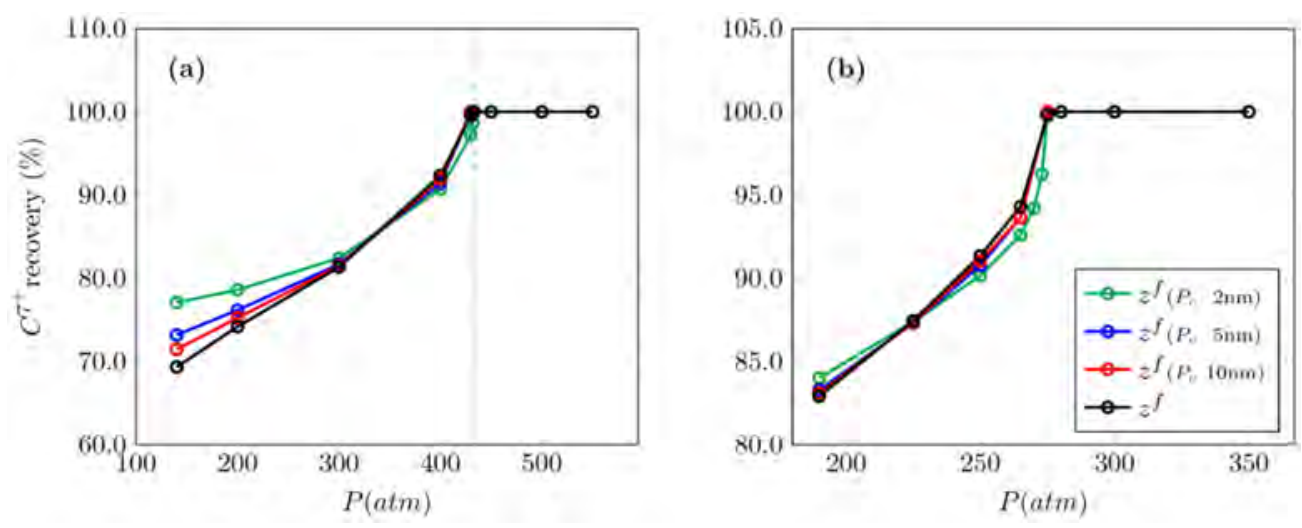

Figure 6-(a) Eagle Ford fluid and (b) Bakken fluid $C^{7+}$ recoveries at different pressures.
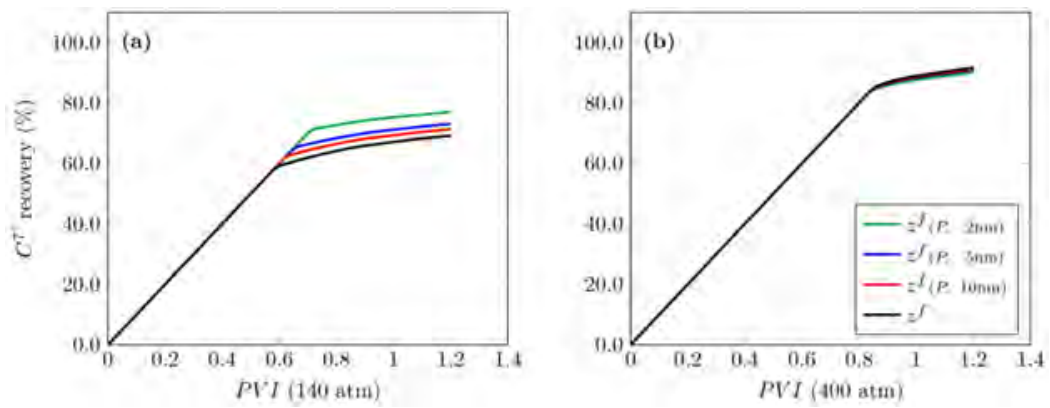

Figure 7- $C^{7+}$ recoveries recoveries at different PVI for (a) $140 \mathrm{~atm}$ and (b) $400 \mathrm{~atm}$ injecting pressures..

\section{Slimtube Simulation Including Adsorption}

1D-slimtube simulations including adsorption effects on phase behavior were studied to obtain an insight on displacement processes and evaluate the differences on terms of MMP achieved. The 500 (scf/tb) GOR Eagle Ford fluid that was used in the PVT simulations was tested here too at different capillary radii. The implicit scheme (ISPU) together with the flash procedure including adsorption was employed. The 500 grid blocks were used for all the simulations. Similar to the results including adsorption, the results were extrapolated to the infinity grid block case (Stalkup 1990). Pure methane at $400 \mathrm{~K}$ and different pressures was used as injecting gas. Fig. 8 shows the results for $300 \mathrm{~atm}$ including adsorption at different PVI. The plotted gas saturation refers to the relative volume saturation of the bulk phases, where it is assumed that the adsorbed phase do not occupy any volume of the system. As PVI increases, the solution curve travels smoothly along the slimtube with no apparent numerical problems. The phase mole fraction profiles show a similar behavior to that of the gas saturation. Except for the adsorbed phase, which remains almost constant during the simulation. This does not mean that the composition of the adsorbed phase remains unchanged. We can inspect the composition changes at different stages of the injection process. The leading front sweeps most of the components except for the heaviest ones. Moreover, in the trailing front, adsorption of the heaviest component occurs in order to swap it for 'lighter' components. Leaving almost exclusively the heaviest component. This suggests that a two-way adsorption/desorption process takes place, and not only desorption as one may hope from a production perspective point of view. 

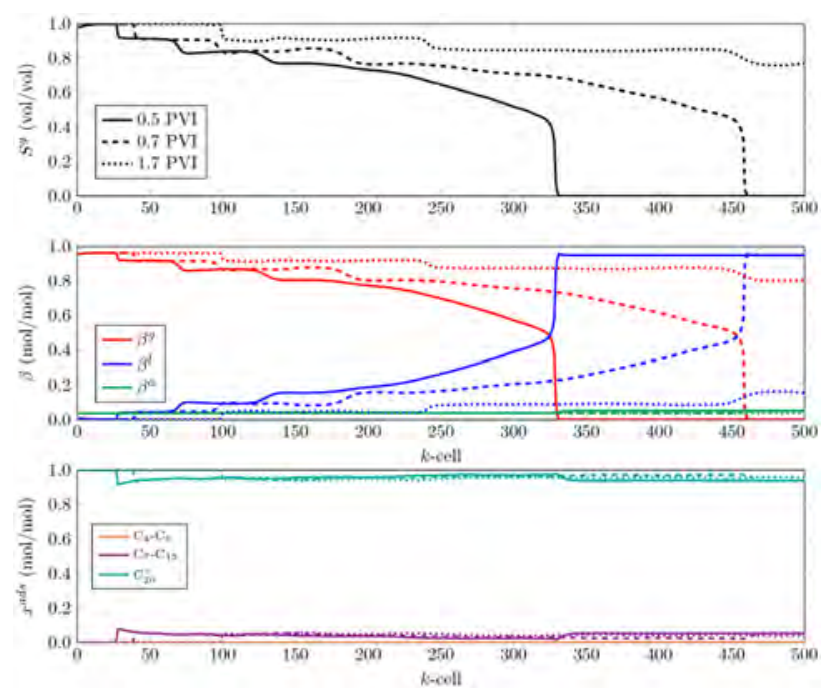

Figure 8-[top] Gas saturation, [middle] phase mole fractions, and [bottom] adsorbed mole fractions displacement profiles after different PVI at $300 \mathrm{~atm}$ for the $\mathbf{5 0 0} \mathrm{scf} / \mathrm{stb}$ GOR Eagle Ford fluid. Case $z^{f}$ including adsorption effects using $r_{c}=\mathbf{5} \mathrm{nm}$.

Case II $\left(z^{b}\right)$ and case III $\left(z^{f}\right)$ of Table 1 were also tested to evaluate the differences when the adsorption effect is neglected during injection. Results of the displacement profiles at 300 atm of injection pressures is presented in Fig. 9 and Fig. 10 for 0.5 PV and 1.2 PV respectively. The differences on the profiles in Fig. 9 are from low to moderate on the volume gas saturation, phase mole fractions, and densities. As the PVI increases, the displacement of phase mole fractions and overall cell compositions $\left(z^{\text {all }}\right)$ move considerably slower when considering adsorption as shown in Fig. 10. Moreover, a large gas-liquid region is left inside the tube consisting of heavy components and methane. After the intermediate components are produced, a binary mixture of methane and the heaviest component left in the system will likely form a remaining liquid phase. In contrast, a single-phase region at the injection end of the slimtube is found for the cases without adsorption. Fig. 10 also shows that the adsorbed phase left consists mostly of the heaviest component, which is responsible for the big difference in the $z^{\text {all }}$ composition when compared to the cases without adsorption.
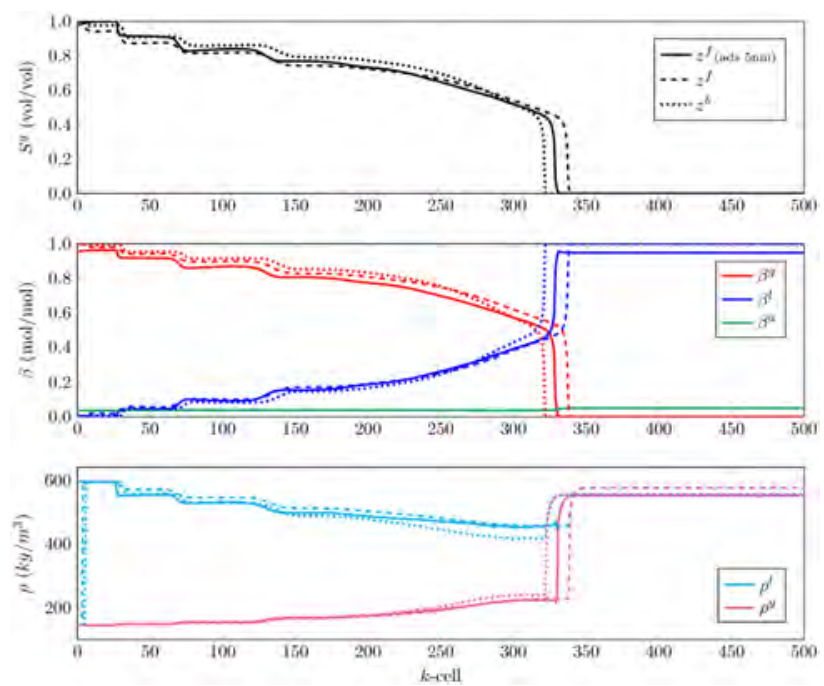

Figure 9-[top] Gas saturation, [middle] phase mole fractions, and [bottom] density displacement profiles after 0.5 PVI at 300 atm for the $500 \mathrm{scf} / \mathrm{stb}$ GOR Eagle Ford fluid. Case I ( $z^{f}$ including adsorption effects using $\left.r_{c}=5 \mathrm{~nm}\right)$, case II ( $\left(z^{b}\right)$, and case III $\left(z^{f}\right)$. 

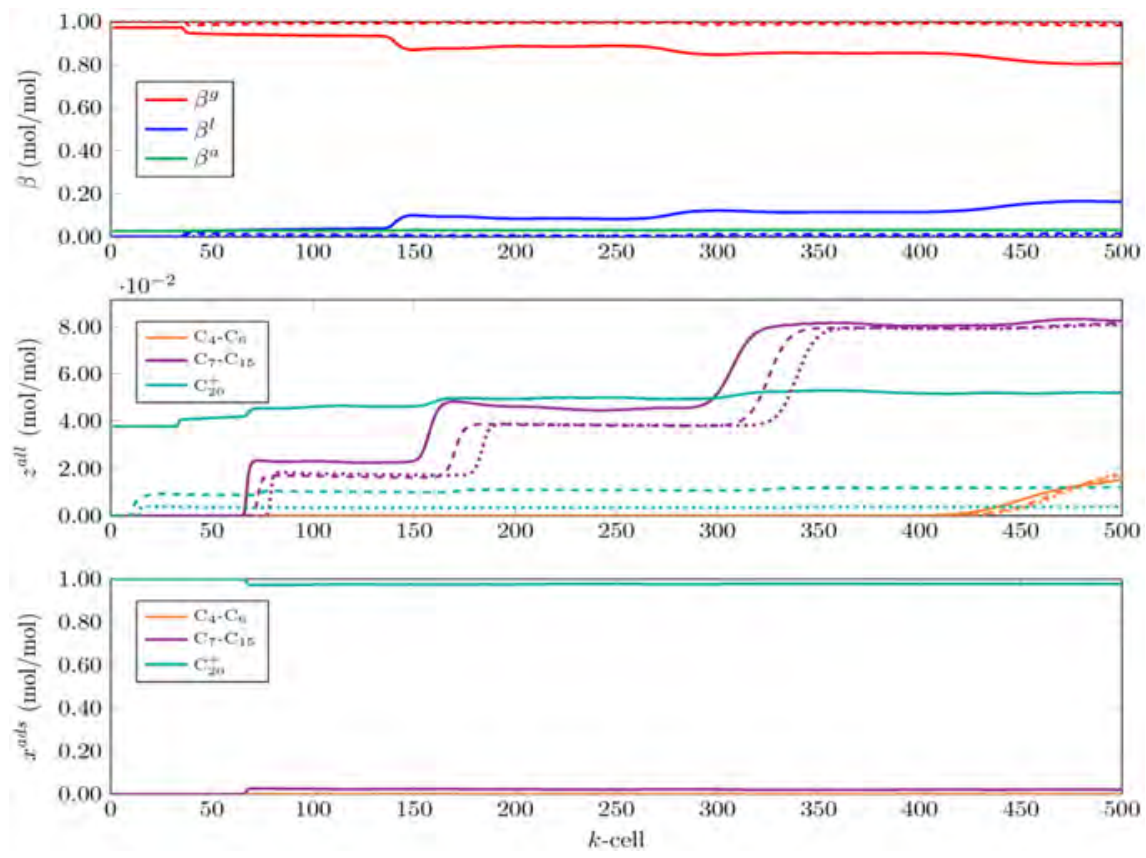

Figure 10-[top] Phase mole fraction, [middle] overall cell mole fraction $z^{\text {all }}$, and [bottom] adsorbed phase mole fraction displacement profiles after $1.2 \mathrm{PVI}$ at $300 \mathrm{~atm}$ for the $500 \mathrm{scf} / \mathrm{stb}$ GOR Eagle Ford fluid. Case I ( $z^{f}$ including adsorption effects using $\left.r_{c}=5 \mathrm{~nm}\right)$, case II $\left(z^{b}\right)$, and case III $\left(z^{f}\right)$.

Fig. 11 shows the results for the injection of methane at $450 \mathrm{~atm}$. The results are considerably different from the ones presented in Fig. 9. When the injection pressure increases, the cases that do not consider adsorption are very close to the MMP. Such miscibility is more easily seen in the saturation and phase mole fractions plots than in the density profiles. The case considering adsorption do not reach miscibility conditions on the bulk phase. This indicates that the adsorbed phase serves as sink/source term for the heavier components that stabilizes the bulk two-phase region at higher pressures.
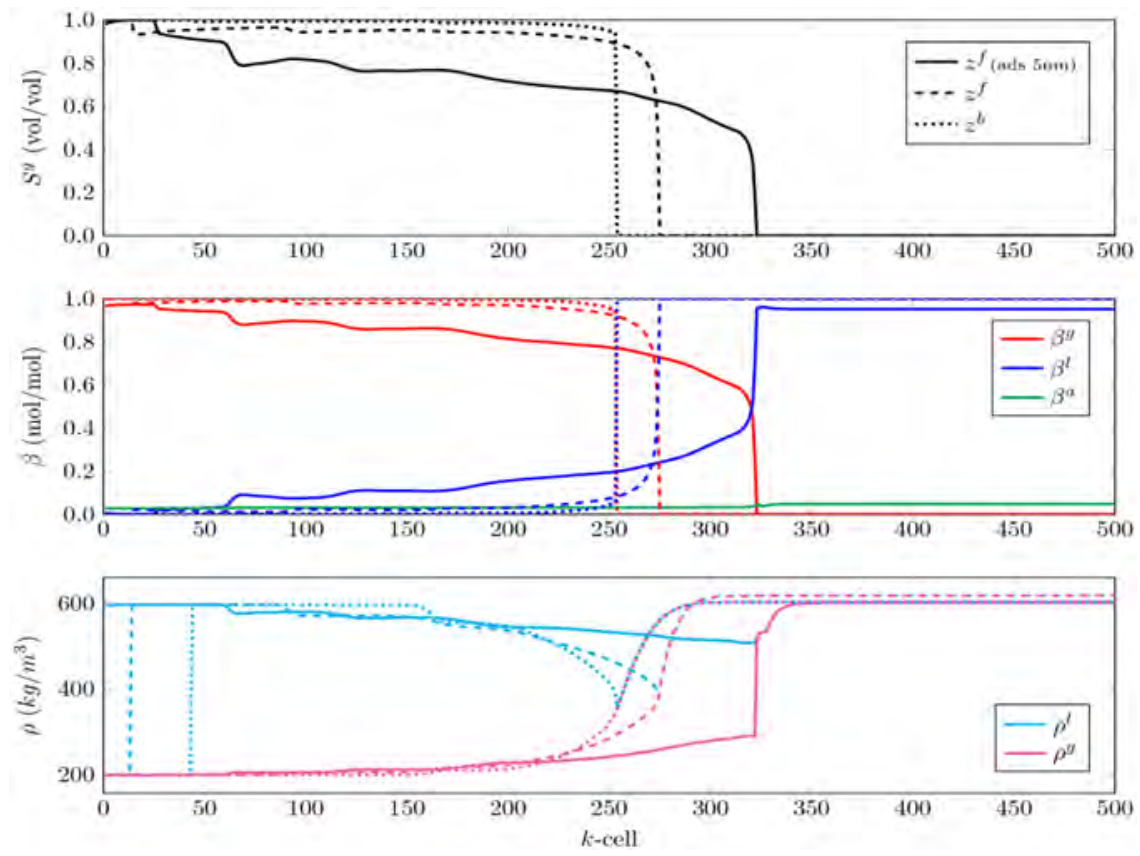

Figure 11-[top] Gas saturation, [middle] phase mole fractions, and [bottom] density displacement profiles after 0.5 PVI at 450 atm for the $500 \mathrm{scf} / \mathrm{stb}$ GOR Eagle Ford fluid. Case I ( $z^{f}$ including adsorption effects using $r_{c}=5 \mathrm{~nm}$ ), case II ( $\left.z^{b}\right)$, and case III $\left(z^{f}\right)$. 
Finally, the recovery for the different cases was calculated at different injection pressures in order to determine the MMP. The results for the $\mathrm{C}^{7+}$ recovery fraction are presented in Fig. 12. It can be observed in Fig. 12a that only the cases without considering adsorption reach full miscibility around $380 \mathrm{~atm}$ for $z^{b}$ and $430 \mathrm{~atm}$ for $z^{f}$, whereas the case considering adsorption show a smooth increased with respect the pressure without achieving a full miscible displacement. The smooth increase of the recovery curve is observed for the two capillary radii studied. As the capillary radii increases, the surface to volume area decreases and so does the effect of adsorption. Fig. 12b shows the recovery at different PVI for an injection pressure of 300 atm. At low PVI, the recovery is very similar for all the curves, but the difference becomes larger at higher PVI until a change of slope is encountered. After this point the differences appear to remain constant.
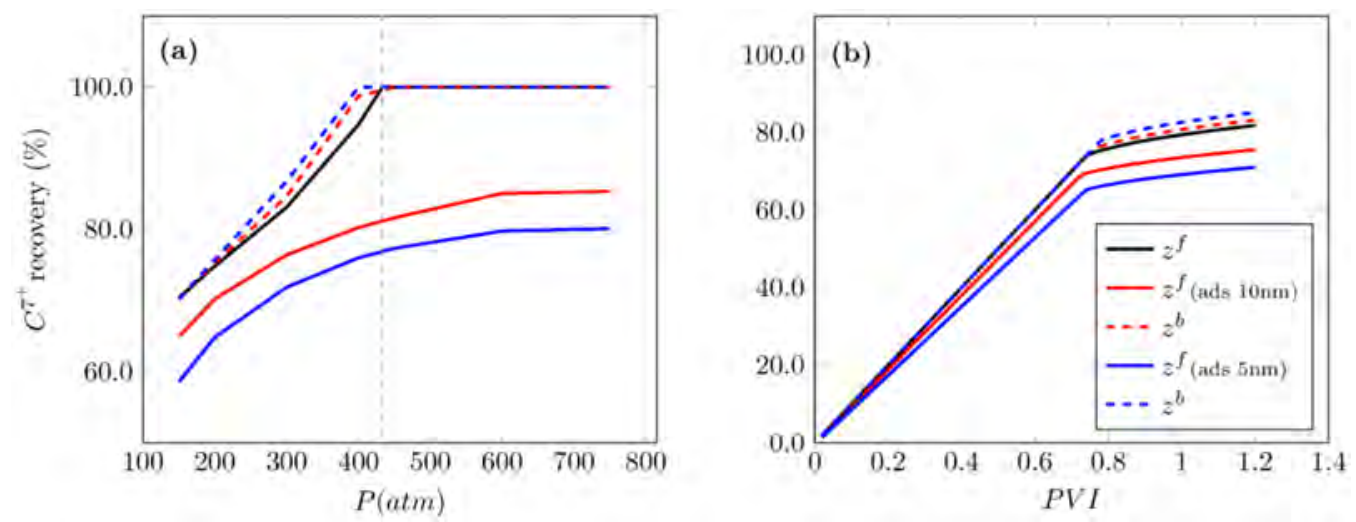

Figure 12- $C^{7+}$ recoveries at different (a) Pressures and (b) PVI for an injecting pressure of $\mathbf{3 0 0} \mathrm{atm}$ for the $\mathbf{5 0 0} \mathrm{scf} / \mathrm{stb}$ GOR fluid. Cases at different capillary radii.

While the $\mathrm{C}_{7+}$ is a good indication of the produced oil, it can also be misleading when considering adsorption. The previous findings show that the heaviest component, in this case the $\mathrm{C} 20$ fraction remains almost exclusively in the adsorbed phase. This can distort the results and may not indicate the percentage of oil produced. If one analyzes the $\mathrm{C} 7+$ fraction without the heaviest component, namely $\mathrm{C} 7-\mathrm{C} 15$, the results will reflect better the percentage of oil recovered. Fig. 13, shows the results for the case of $r_{c}=5 \mathrm{~nm}$. The recovery is much closer than those presented in Fig. 12, but some difference remain unchanged. The most important is the absence of a miscible displacement at higher pressures. Instead, a smooth increase of the recovery is observed reaching almost $100 \%$ at very high pressures. Before $350 \mathrm{~atm}$, the recovery curves are comparable and this is reflected on Fig. 9 and Fig. 10.
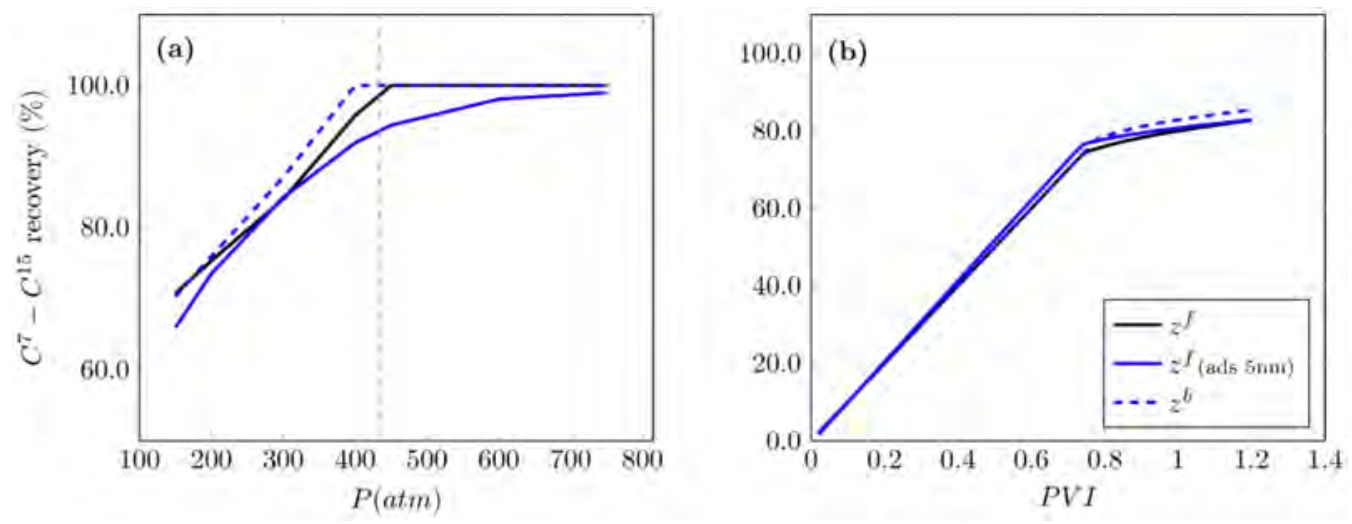

Figure 13- $C^{7}-C^{20}$ recoveries at different (a) Pressures and (b) PVI for an injecting gas pressure of $300 \mathrm{~atm}$ for the $500 \mathrm{scf} / \mathrm{stb}$ GOR fluid. Capillary radius $r_{c}=\mathbf{5 m}$. 


\section{Conclusions}

Porous media effects, namely adsorption and capillary pressure, play an important role during oil production from tight and shale reservoirs. The extent of the effect on the fluid properties and phase behavior depends on the characteristics of the porous media, fluid description, and type of application. Here we investigated depletion scenarios using PVT simulations, and gas injection scenarios using 1D-slimtube simulations. For the depletion, the capillary pressure shows to be the most important effect for oils and the adsorption effect for gas condensate fluids. DL results show that the capillary pressure delays the single-phase region during production improving the final oil recovery. It also yields a lighter oil phase, compared to the cases without capillary pressure. The higher pressure in the gas with respect to the liquid allows the migration of lighter components to the liquid phase. The adsorption does not play a major role during the oil depletion, however, careful attention to the 'correct' composition is needed. If adsorption effects are neglected during depletion, it is still crucial to distinguish between the bulk phase composition and overall composition. As long as the bulk phase composition (case II) is used during the PVT experiment instead of the overall composition (case III), the results should be close enough to the real scenario (case I). For the gas condensate system, the adsorption plays a major role and the influence of the capillary pressure is moderate. Leaning of the gas is observed during production, yielding a lower oil to gas ratio and lower liquid dropout. Desorption of the lighter components occur as the pressure decreases, resulting in a modified saturation pressure and oil composition. Compared to the oil production case, the gas condensate shows larger porous media effects. Even if the composition of the system is correctly selected before the PVT experiment, important adsorption/ desorption processes will take place and have a large impact on the results. The results for the slimtube simulation including capillary pressure show differences at injected pressures lower than the MMP. The capillary effect is only important far from miscibility, where an increase on the oil recovery is observed. The gas density increases and the liquid density decreases at low capillary radii. At the calculated bulk MMP, capillary pressure vanishes resulting in matching MMP for all the cases at different capillary radii. The results of the slimtube simulations including adsorption provide a useful insight to the adsorption/ desorption process taking place and the expected oil recovery if gas injection is considered. The flash procedure used for the simulation, allows to couple the phase split calculation with adsorption resulting in a more rigorous approach. The results show that the recovery decreases if adsorption is considered, compared to the cases without adsorption. This is mainly due to adsorption of heavy components, and desorption of lighter components during the gas injection. The heavy components stay in the adsorbed phase, and will not likely be recovered at high injection pressures. Moreover, the displacement profiles and recovery curves show that a miscible region is not obtained when considering adsorption. The results suggest that the adsorbed phase serves as a sink/source of components that stabilizes the two-phase region. After the intermediate components are produced, the binary mixture of methane and the heaviest component left in the system will likely form a small amount of liquid phase at high pressures. The recovery results using $C^{7+}$ fraction show huge differences when considering adsorption. However, it is recommended to distinguish between the oil components that can be recovered by injection and those that are adsorbed permenantly in the rock. The latter is represented by the heaviest component in our simulation case, but we should bear in mind that this pseudocomponent is a group of the heaviest components. If the recovery calculation excludes the heaviest part in the oil, the values can be significantly higher.

\section{Acknowledgements}

The authors are grateful to the Danish Hydrocarbon Research and Technology Centre (DHRTC) for their support and technical collaboration. 


\section{References}

Cabral, V. F., Castier, M., \& Tavares, F. W. 2005. Thermodynamic equilibrium in systems with multiple adsorbed and bulk phases. Chemical Engineering Science, 60 (6), 1773-1782. https://doi.org/10.1016/j.ces.2004.11.007

Dong, X., Liu, H., Hou, J., Wu, K., \& Chen, Z. 2016. Phase Equilibria of Confined Fluids in Nanopores of Tight and Shale Rocks Considering the Effect of Capillary Pressure and Adsorption Film. Industrial \& Engineering Chemistry Research, 55 (3), 798-811. https://doi.org/10.1021/acs.iecr.5b04276

Fisher, L. R., \& Israelachvili, J. N. 1981. Experimental Studies on the Applicability of the Kelvin Equation to Highly Curved Concave Menisci. Journal of Colloid and Interface Science, 80 (2), 528-541. https:// doi.org/10.1016/0021-9797(81)90212-5

Ganjdanesh, R., Yu, W., Fiallos, M. X., Kerr, E., Sepehrnoori, K., \& Ambrose, R. 2019. Gas Injection EOR in Eagle Ford Shale Gas Condensate Reservoirs. Presented at the Unconventional Resources Technology Conference, Colorado 22-24 July. doi:10.105530/urtec-2019-987

Gasparik, M., Rexer, T. F. T., Aplin, A. C., Billemont, P., De Weireld, G., Gensterblum, Y., Zhang, T. 2014. First international inter-laboratory comparison of high-pressure $\mathrm{CH} 4, \mathrm{CO} 2$ and $\mathrm{C} 2 \mathrm{H} 6$ sorption isotherms on carbonaceous shales. International Journal of Coal Geology, 132 (June 2015), 131-146. https://doi.org/10.1016/j.coal.2014.07.010

Hamdi, H., Clarkson, C. R., Ghanizadeh, A., Ghaderi, S. M., Vahedian, A., Riazi, N., \& Esmail, A. 2018. Huff-N-Puff Gas Injection Performance in Shale Reservoirs: A Case Study from Duvernay Shale in Alberta, Canada. Presented at the Unconventional Resources Technology Conference. Houston, Texas 23-25 July. doi:10.15530/URTEC-2018-2902835

Kumar, A., Dusterhoft, R., \& Siddiqui, S. 2013. Completion and production strategies for liquids-rich wells in ultra-lowpermeability reservoirs. Presented at SPE Annual Technical Conference and Exhibition. New Orleans, Louisiana, 30 September-2 October. SPE 166177

Li, L., Sheng, J. J., \& Sheng, J. 2016. Optimization of Huff-n-Puff Gas Injection to Enhance Oil Recovery in Shale Reservoirs. Presented at SPE Low Perm Symposium held in Denver, Colorado, 5-6 May. SPE-180219-MS. doi:10.2118/180219-MS

Luo, S., Lutkenhaus, J. L., \& Nasrabadi, H. 2016a. Confinement-Induced Supercriticality and Phase Equilibria of Hydrocarbons in Nanopores. Langmuir, 32 (44), 11506-11513. https://doi.org/10.1021/acs.langmuir.6b03177

Luo, S., Nasrabadi, H., \& Lutkenhaus, J. L. 2016b. Effect of Confinement on the Bubble Points of Hydrocarbons in Nanoporous Media. AIChE Journal, 62(5). https://doi.org/10.1002/aic

Luo, S., Lutkenhaus, J. L., \& Nasrabadi, H. 2018. Use of Differential Scanning Calorimetry to Study Phase Behavior of Hydrocarbon Mixtures in Nano-scale Porous Media. Journal of Petroleum Science and Engineering, 163(September 2016), 731-738. https://doi.org/10.1016/j.petrol.2016.12.019

Meng, X., Sheng, J. J., \& Yu, Y. 2015. Evaluation of Enhanced Condensate Recovery Potential in Shale Plays by Huff-nPuff Gas Injection. Presented at the SPE Eastern Regional Meeting held in Morgantown, West Virginia, 13-15 October. SPE-177283. doi:10.2118/177283-MS

Nojabaei, B., Johns, R. T., Chu, L., \& Corporation, H. (2013). Effect of Capillary Pressure on Phase Behavior in Tight Rocks and Shales. SPE Journal, August, 281-289.

Pathak, M., Kweon, H., Deo, M., and Huang, H. 2017a. Kerogen Swelling and Confinement: Its implication on Fluid Thermodynamic Properties in Shales. Sci. Rep. 7 (1): 12530. https://doi.org/10.1038/s41598-017-12982-4.

Pathak, M., Kweon, H., Panja, P., Velasco, R., and Deo, M. D. 2017b. Suppression in the Bubble Points of Oils in Shales Combined Effect of Presence of Organic Matter and Confinement. Presented at the SPE Unconventional Resources Conference, Calgary, Alberta, Canada. 2017/2/15/. https://doi.org/10.2118/185080-MS.

Pathak, M., Velasco, R., Panja, P., and Deo, M. D. 2017c. Experimental Verification of Changing Bubble Points of Oils in Shales: Effect of Preferential Absorption by Kerogen and Confinement of Fluids. Presented at the SPE Annual Technical Conference and Exhibition, San Antonio, Texas, USA. 2017/10/9/. https://doi.org/10.2118/187067-MS.

Regueira, T., Sandoval, D. R., Stenby, E. H., \& Yan, W. 2019. Experimental Study of the Phase Behavior of Hydrocarbon Fluids in Porous Media at Atmospheric and Elevated Pressures. Presented at the Unconventional Resources Technology Conference (URTeC). https://doi.org/10.15530/urtec-2019-534

Sandoval, D. R., Yan, W., Michelsen, M. L., \& Stenby, E. H. (2018). Influence of Adsorption and Capillary Pressure on Phase Equilibria inside Shale Reservoirs. Energy and Fuels, 32(3), 2819-2833. https://doi.org/10.1021/ acs.energyfuels. $7 \mathrm{~b} 03274$

Sandoval, D. R., Yan, W., Michelsen, M. L., \& Stenby, E. H. (2016). The phase envelope of multicomponent mixtures in the presence of a capillary pressure difference. Industrial \& Engineering Chemistry Research, acs.iecr.6b00972. https://doi.org/10.1021/acs.iecr.6b00972

Shapiro, A. a., \& Stenby, E. H. (1998). Potential Theory of Multicomponent Adsorption. Journal of Colloid and Interface Science, 157(201), 146-157.

Sugden, S. (1924). A Relation Between Surface Tension, Density, and Chemical Composition. J. Chem. Soc., Trans., 125(2), 1177-1189. https://doi.org/10.1039/CT9242501177 
Stalkup, F.I., Lo, L.L., Dean, R.H., 1990. Sensitivity to Gridding of Miscible flood Predictions Made with Upstream Differenced Simulations. Paper presented at the SPE/DOE seventh Symposium on Enhanced Oil Recovery held in Tulsa, Oklahoma, April 22-25. SPE 20178.

Thiele, M.R., Edwards, M.G., 2001. Physically Based Higher Order Godunov Schemes for Compositional Simulation. Paper presented at the SPE Reservoir Simulation Symposium held in Houston, Texas, February 11-14. SPE 66403.

Wang, L., \& Yu, W. 2019. Gas Huff and Puff Process in Eagle Ford Shale: Recovery Mechanism Study and Optimization. Presented at the SPE Oklahoma City Oil and Gas Symposium held in Oklahoma City, Oklahoma, USA, 9-10 April. SPE-195185-MS.

Wang, Y., Tsotsis, T. T., \& Jessen, K. (2015). Competitive Sorption of Methane/Ethane Mixtures on Shale: Measurements and Modeling. Industrial and Engineering Chemistry Research, 54(48), 12187-12195. https://doi.org/10.1021/ acs.iecr.5b02850

Yan, W., Michlesen, M. L., \& Stenby, E. H. (2012). Calculation of minimum miscibility pressure using fast slimtube simulation. Presented at the SPE Symposium on Improved Oil Recovery held in Tulsa, Oklahoma, 14-18 April. SPE 153758 . 


\section{Appendix A}

\section{Reservoir Fluids Parameters}

Table A-1-EoS and Langmuir parameters for the Eagle Ford black oil fluids. (Orangi et al. 2008)

\begin{tabular}{|c|c|c|c|c|c|c|c|c|c|c|}
\hline \multicolumn{2}{|c|}{ Component $T_{c}(\mathrm{~K})$} & \multirow{2}{*}{$\begin{array}{c}\boldsymbol{P} \text { (atm) } \\
45.80\end{array}$} & \multirow{2}{*}{$\begin{array}{c}\boldsymbol{\Omega} \\
0.0130\end{array}$} & \multirow{2}{*}{$\begin{array}{r}\begin{array}{c}\text { MW } \\
(\mathrm{g} / \mathrm{mol})\end{array} \\
16.04\end{array}$} & \multirow{2}{*}{$\begin{array}{r}\text { Parachor } \\
74.05\end{array}$} & \multirow{2}{*}{$\begin{array}{c}\boldsymbol{E}^{a} \\
-1776.0\end{array}$} & \multirow{2}{*}{$\begin{array}{c}A^{S} \\
-8.73\end{array}$} & \multirow{2}{*}{$\begin{array}{c}\boldsymbol{n}^{\max } \\
0.0130\end{array}$} & \multirow{2}{*}{$\begin{array}{c}z^{f}(\mathbf{5 0 0} \\
\text { stb/scf) }\end{array}$} & \multirow{2}{*}{$\begin{array}{l}z^{f}(\mathbf{1 0 0 0} \\
\text { stb/scf) }\end{array}$} \\
\hline $\mathrm{C}_{1}$ & 190.7 & & & & & & & & & \\
\hline $\mathrm{N}_{2}$ & 126.2 & 33.50 & 0.0400 & 28.01 & 61.12 & -1586.8 & -8.38 & 0.0400 & 0.00073 & 0.00104 \\
\hline $\mathrm{C}_{2}$ & 305.4 & 48.20 & 0.0986 & 30.07 & 112.91 & -2087.6 & -8.33 & 0.0986 & 0.04314 & 0.05882 \\
\hline $\mathrm{C}_{3}$ & 369.9 & 42.01 & 0.1524 & 44.10 & 154.03 & -2399.2 & -7.95 & & & 0.04506 \\
\hline $\mathrm{CO}_{2}$ & 304.2 & 72.90 & 0.2250 & 44.01 & 82.00 & -2750.2 & -7.95 & & & 0.01821 \\
\hline $\mathrm{iC}_{4}$ & 408.1 & 36.00 & 0.1848 & 58.12 & & -2710.6 & -7.60 & & 0.01350 & 0.01298 \\
\hline $\mathrm{nC}_{4}$ & 425.2 & 37.47 & 0.2010 & 58.12 & 193.90 & -2710.6 & -7.60 & 0.2010 & 0.03382 & 0.02978 \\
\hline $\mathrm{iC}_{5}$ & 460.4 & 32.90 & 0.2223 & 72.15 & 236.00 & -3022.2 & -7.28 & 0.2223 & 0.01805 & 0.01507 \\
\hline $\mathrm{nC}_{5}$ & 469.8 & 33.31 & 0.2539 & 72.15 & 236.00 & -3022.2 & -7.28 & & & 0.01711 \\
\hline $\mathrm{nC}_{6}$ & 507.9 & 29.92 & 0.3007 & 86.18 & 276.71 & -3333.8 & -6.99 & 0.3007 & 0.04623 & 0.03280 \\
\hline $\mathrm{C}_{7}^{+}$ & 589.2 & 27.41 & 0.3673 & 114.40 & 341.41 & -3960.6 & -6.48 & 0.3739 & 0.16297 & 0.11563 \\
\hline $\mathrm{C}_{11}^{+}$ & 679.8 & 20.94 & 0.5491 & 166.60 & 495.49 & -5120.1 & -5.84 & 0.5260 & 0.12004 & 0.08940 \\
\hline $\mathrm{C}_{15}^{+}$ & 760.2 & 16.43 & 0.6435 & 230.10 & 682.93 & -6530.5 & -5.57 & 0.6979 & 0.10044 & 0.07127 \\
\hline $\mathrm{C}_{20}{ }^{+}$ & 896.8 & 10.28 & 0.7527 & 409.20 & 1211.60 & $\begin{array}{c}- \\
10508.4\end{array}$ & -5.30 & 1.0456 & 0.07306 & 0.04762 \\
\hline
\end{tabular}

Table A-2-EoS and Langmuir parameters for the Eagle Ford gas condensate fluid. (Orangi et al. 2008)

\begin{tabular}{cccccccccc}
\hline Component & $\boldsymbol{T}_{\boldsymbol{c}}(\mathbf{K})$ & $\boldsymbol{P}(\mathbf{a t m})$ & $\boldsymbol{\Omega}$ & $\begin{array}{c}\text { MW }(\mathbf{g} / \\
\mathbf{m o l})\end{array}$ & Parachor & $\boldsymbol{E}^{a}$ & $\boldsymbol{A}^{S}$ & $\boldsymbol{n}^{\max }$ & $\begin{array}{c}\boldsymbol{z}^{f}(\mathbf{1 5 0} \\
\text { MMscf/ } \\
\text { stb) }\end{array}$ \\
\hline $\mathrm{C}_{1}$ & 190.7 & 45.80 & 0.0130 & 16.04 & 74.05 & -1776.0 & -8.73 & 0.4226 & 0.6588 \\
$\mathrm{~N}_{2}$ & 126.2 & 33.50 & 0.0400 & 28.01 & 61.12 & -1586.8 & -8.38 & 0.4671 & 0.0015 \\
$\mathrm{C}_{2}$ & 305.4 & 48.20 & 0.0986 & 30.07 & 112.91 & -2087.6 & -8.33 & 0.2777 & 0.0834 \\
$\mathrm{C}_{3}$ & 369.9 & 42.01 & 0.1524 & 44.10 & 154.03 & -2399.2 & -7.95 & 0.1998 & 0.0467 \\
$\mathrm{CO}_{2}$ & 304.2 & 72.90 & 0.2250 & 44.01 & 82.00 & -2750.2 & -7.95 & 0.4217 & 0.0269 \\
$\mathrm{iC}_{4}$ & 408.1 & 36.00 & 0.1848 & 58.12 & 193.90 & -2710.6 & -7.60 & 0.1552 & 0.0105 \\
$\mathrm{nC}_{4}$ & 425.2 & 37.47 & 0.2010 & 58.12 & 193.90 & -2710.6 & -7.60 & 0.1551 & 0.0183 \\
$\mathrm{iC}_{5}$ & 460.4 & 32.90 & 0.2223 & 72.15 & 236.00 & -3022.2 & -7.28 & 0.1257 & 0.0083 \\
$\mathrm{nC}_{5}$ & 469.8 & 33.31 & 0.2539 & 72.15 & 236.00 & -3022.2 & -7.28 & 0.1248 & 0.0079
\end{tabular}




\begin{tabular}{ccccccccccc}
\hline Component & $\boldsymbol{T}_{\boldsymbol{c}} \mathbf{( K )}$ & $\boldsymbol{P}(\mathbf{a t m})$ & $\boldsymbol{\Omega}$ & $\begin{array}{c}\text { MW (g/ } \\
\mathbf{m o l})\end{array}$ & Parachor & $\boldsymbol{E}^{a}$ & $A^{S}$ & $\boldsymbol{n}^{\max }$ & $\begin{array}{c}\boldsymbol{z}^{f}(\mathbf{1 5 0} \\
\mathbf{M M s c f} / \\
\mathbf{s t b})\end{array}$ \\
\hline $\mathrm{nC}_{6}$ & 507.9 & 29.92 & 0.3007 & 86.18 & 276.71 & -3333.8 & -6.99 & 0.1037 & 0.0119 \\
$\mathrm{C}_{7}{ }^{+}$ & 584.1 & 27.80 & 0.3673 & 112.00 & 334.32 & -3907.3 & -6.52 & 0.0837 & 0.0763 \\
$\mathrm{C}_{11}{ }^{+}$ & 692.2 & 20.20 & 0.5491 & 175.00 & 520.28 & -5306.6 & -5.77 & 0.0513 & 0.0455 \\
$\mathrm{C}_{15}{ }^{+}$ & 737.6 & 17.62 & 0.6435 & 210.00 & 623.60 & -6084.0 & -5.59 & 0.0420 & 0.0028 \\
$\mathrm{C}_{20}{ }^{+}$ & 781.0 & 15.40 & 0.7527 & 250.00 & 741.67 & -6972.5 & -5.50 & 0.0347 & 0.0014 \\
\hline
\end{tabular}

Table A-3-EoS and Langmuir parameters for the Eagle Ford gas condensate fluid. (Nojabaei et al. 2013)

\begin{tabular}{cccccccccc}
\hline Component & $\boldsymbol{T}_{\boldsymbol{c}}(\mathbf{K})$ & $\boldsymbol{P}(\mathbf{a t m})$ & $\boldsymbol{\Omega}$ & $\begin{array}{c}\text { MW (g/ } \\
\mathbf{m o l})\end{array}$ & Parachor & $\boldsymbol{E}^{a}$ & $\boldsymbol{A}^{S}$ & $\boldsymbol{n}^{\max }$ & $\boldsymbol{z}^{f}$ \\
\hline $\mathrm{C}_{1}$ & 186.3 & 45.16 & 0.0102 & 16.54 & 74.80 & -1787.0 & -8.71 & 0.4226 & 0.3674 \\
$\mathrm{C}_{2}$ & 305.5 & 49.78 & 0.1028 & 30.43 & 107.70 & -2095.7 & -8.32 & 0.2777 & 0.1489 \\
$\mathrm{C}_{3}$ & 370.0 & 42.46 & 0.1520 & 44.10 & 151.90 & -2399.1 & -7.95 & 0.1998 & 0.0933 \\
$\mathrm{C}_{4}$ & 421.8 & 37.68 & 0.1894 & 58.12 & 189.60 & -2710.7 & -7.60 & 0.1552 & 0.0575 \\
$\mathrm{C}_{5}-\mathrm{C}_{6}$ & 486.4 & 31.80 & 0.2684 & 78.30 & 250.20 & -3158.7 & -7.15 & 0.1136 & 0.0641 \\
$\mathrm{C}_{7}-\mathrm{C}_{12}$ & 585.1 & 25.05 & 0.4291 & 120.56 & 350.20 & -4097.5 & -6.38 & 0.0743 & 0.1585 \\
$\mathrm{C}_{13}-\mathrm{C}_{21}$ & 740.1 & 17.21 & 0.7203 & 220.72 & 590.20 & -6322.0 & -5.57 & 0.0404 & 0.0733 \\
$\mathrm{C}_{22}-\mathrm{C}_{80}$ & 1024.7 & 13.11 & 1.0159 & 443.52 & 1216.80 & - & -8.80 & 0.0222 & 0.0370 \\
& & & & & & 11270.7 & & & \\
\hline
\end{tabular}

Table A-4-Non zero binary interaction parameters for fluids in table A-1

\begin{tabular}{cccccccccc}
\hline Component & $\mathbf{C}_{1}$ & $\mathbf{N}_{2}$ & $\mathbf{C}_{2}$ & $\mathbf{C}_{3}$ & $\mathbf{C O}_{2}$ & $\mathbf{i C}_{4}$ & $\mathbf{n C}_{4}$ & $\mathbf{i C}_{5}$ & $\mathbf{n C}_{5}$ \\
\hline $\mathrm{C}_{1}$ & 0.000 & -- & -- & -- & -- & -- & -- & -- & -- \\
$\mathrm{N}_{2}$ & 0.036 & 0.000 & -- & -- & -- & -- & -- & -- & -- \\
$\mathrm{C}_{2}$ & 0.000 & 0.050 & 0.000 & -- & -- & -- & -- & -- & -- \\
$\mathrm{C}_{3}$ & 0.000 & 0.080 & 0.000 & 0.000 & -- & -- & -- & -- & -- \\
$\mathrm{CO}_{2}$ & 0.100 & -0.020 & 0.130 & 0.135 & 0.000 & -- & -- & -- & - \\
$\mathrm{iC}_{4}$ & 0.000 & 0.095 & 0.000 & 0.000 & 0.130 & 0.000 & -- & -- & -- \\
$\mathrm{nC}_{4}$ & 0.000 & 0.090 & 0.000 & 0.000 & 0.130 & 0.000 & 0.000 & -- & -- \\
$\mathrm{iC}_{5}$ & 0.000 & 0.095 & 0.000 & 0.000 & 0.125 & 0.000 & 0.000 & 0.000 & -- \\
$\mathrm{nC}_{5}$ & 0.000 & 0.100 & 0.000 & 0.000 & 0.125 & 0.000 & 0.000 & 0.000 & 0.000 \\
$\mathrm{nC}_{6}$ & 0.000 & 0.100 & 0.000 & 0.000 & 0.125 & 0.000 & 0.000 & 0.000 & 0.000
\end{tabular}




\begin{tabular}{cccccccccc}
\hline Component & $\mathbf{C}_{\mathbf{1}}$ & $\mathbf{N}_{\mathbf{2}}$ & $\mathbf{C}_{\mathbf{2}}$ & $\mathbf{C}_{\mathbf{3}}$ & $\mathbf{C O}_{\mathbf{2}}$ & $\mathbf{i C}_{\mathbf{4}}$ & $\mathbf{n C}_{\mathbf{4}}$ & $\mathbf{i C}_{\mathbf{5}}$ & $\mathbf{n C}_{\mathbf{5}}$ \\
\hline $\mathrm{C}_{7}{ }^{+}$ & 0.024 & 0.148 & 0.019 & 0.014 & 0.111 & 0.010 & 0.010 & 0.005 & 0.005 \\
$\mathrm{C}_{11^{+}}$ & 0.051 & 0.202 & 0.041 & 0.031 & 0.094 & 0.020 & 0.020 & 0.010 & 0.010 \\
$\mathrm{C}_{15}{ }^{+}$ & 0.062 & 0.223 & 0.049 & 0.037 & 0.089 & 0.025 & 0.025 & 0.012 & 0.012 \\
$\mathrm{C}_{20}{ }^{+}$ & 0.074 & 0.247 & 0.059 & 0.044 & 0.082 & 0.029 & 0.029 & 0.015 & 0.015 \\
\hline
\end{tabular}

Table A-5-Non zero binary interaction parameters for fluid in table A-2

\begin{tabular}{cccccccccc}
\hline Component & $\mathbf{C}_{\mathbf{1}}$ & $\mathbf{N}_{\mathbf{2}}$ & $\mathbf{C}_{\mathbf{2}}$ & $\mathbf{C}_{\mathbf{3}}$ & $\mathbf{C O}_{\mathbf{2}}$ & $\mathbf{i \mathbf { C } _ { \mathbf { 4 } }}$ & $\mathbf{n C}_{\mathbf{4}}$ & $\mathbf{i \mathbf { C } _ { \mathbf { 5 } }}$ & $\mathbf{n C}_{\mathbf{5}}$ \\
\hline $\mathrm{C}_{1}$ & 0.000 & -- & -- & -- & -- & -- & -- & -- & -- \\
$\mathrm{N}_{2}$ & 0.036 & 0.000 & -- & -- & -- & -- & -- & -- & -- \\
$\mathrm{C}_{2}$ & 0.000 & 0.050 & 0.000 & -- & -- & -- & -- & -- & -- \\
$\mathrm{C}_{3}$ & 0.000 & 0.080 & 0.000 & 0.000 & -- & -- & -- & -- & -- \\
$\mathrm{CO}_{2}$ & 0.100 & -0.020 & 0.130 & 0.135 & 0.000 & -- & -- & -- & -- \\
$\mathrm{iC}_{4}$ & 0.000 & 0.095 & 0.000 & 0.000 & 0.130 & 0.000 & -- & -- & -- \\
$\mathrm{nC}_{4}$ & 0.000 & 0.090 & 0.000 & 0.000 & 0.130 & 0.000 & 0.000 & -- & -- \\
$\mathrm{iC}_{5}$ & 0.000 & 0.095 & 0.000 & 0.000 & 0.125 & 0.000 & 0.000 & 0.000 & -- \\
$\mathrm{nC}_{5}$ & 0.000 & 0.100 & 0.000 & 0.000 & 0.125 & 0.000 & 0.000 & 0.000 & 0.000 \\
$\mathrm{nC}_{6}$ & 0.000 & 0.100 & 0.000 & 0.000 & 0.125 & 0.000 & 0.000 & 0.000 & 0.000 \\
$\mathrm{C}_{7}{ }^{+}$ & 0.025 & 0.151 & 0.020 & 0.015 & 0.110 & 0.010 & 0.010 & 0.005 & 0.005 \\
$\mathrm{C}_{11}{ }^{+}$ & 0.049 & 0.197 & 0.039 & 0.029 & 0.097 & 0.019 & 0.019 & 0.010 & 0.010 \\
$\mathrm{C}_{15}{ }^{+}$ & 0.068 & 0.235 & 0.054 & 0.041 & 0.085 & 0.027 & 0.027 & 0.014 & 0.014 \\
$\mathrm{C}_{20}{ }^{+}$ & 0.094 & 0.288 & 0.075 & 0.056 & 0.070 & 0.038 & 0.038 & 0.019 & 0.019 \\
\hline & & & & & & & & &
\end{tabular}

Table A-6-Non zero binary interaction parameters for fluid in table A-3

\begin{tabular}{ccc}
\hline Component & $\mathbf{C}_{\mathbf{1}}$ & $\mathbf{C}_{\mathbf{2}}$ \\
\hline $\mathrm{C}_{1}$ & 0.0000 & -- \\
$\mathrm{C}_{2}$ & 0.0050 & 0.0000 \\
$\mathrm{C}_{3}$ & 0.0035 & 0.0031 \\
$\mathrm{C}_{4}$ & 0.0035 & 0.0031 \\
$\mathrm{C}_{5}-\mathrm{C}_{6}$ & 0.0037 & 0.0031 \\
$\mathrm{C}_{7}-\mathrm{C}_{12}$ & 0.0033 & 0.0026 \\
$\mathrm{C}_{13}-\mathrm{C}_{21}$ & 0.0033 & 0.0026 \\
$\mathrm{C}_{22}-\mathrm{C}_{80}$ & 0.0033 & 0.0026 \\
\hline
\end{tabular}

